\title{
TRADUÇÕES E TRAVESSIAS: POSSIBILIDADES DO (RE)ENCONTRO COM O OUTRO
}

Mériti de Souza e Fernando Aguiar

Mériti de Souza

Doutora em

Psicologia Clínica

pela PUC-SP;

pós-doutorado no

Centro de Estudos

Sociais (CES), da

Universidade de

Coimbra; professora

na graduação e

no Programa de

Pós-graduação em

Psicologia na UFSC.

Fernando Aguiar

Doutor em

Filosofia, Université

Catholique de

Louvain; pós-

doutorado

na Université

Catholique de

Louvain; professor

na graduação e

no Programa de

Pós-graduação em

Psicologia na UFSC.
RESUMO: Procura-se problematizar os impasses relacionados às atividades do profissional que direciona sua escuta para o outro. Para tanto, recorre-se à tragédia de Édipo e analisa-se a tradução realizada face ao enigma da esfinge. Os pressupostos da identidade e da diferença são utilizados para problematizar a alteridade. A análise critica o modelo epistêmico que expurga a metáfora e a tragédia do processo de conhecer.

Palavras-chave: Diferença, identidade, tradução, tragédia.

ABSTRACT: Translations and crossings: possibilities of a (re) encounter with the other. This article problematizes the deadlocks related to the activities of the professional whose listening is guided to the other one. Therefore, he/she falls back to Oedipus Tragedy and analyses the translation done for the Enigma of the Sphinx. The presuppositions of identity and difference are used to render problematize the alterity. This analysis criticizes the epistemic model that expunges the process of metaphor and tragedy from the knowing process.

Keywords: difference, identity, translation, tragedy.

0 jovem Édipo caminhava no monte Cíteron, a fugir do trágico destino que lhe fora profetizado pelo oráculo, quando em meio à travessia, barrando-lhe o caminho, depara-se com uma criatura metade humana, metade animal: "decifra-me ou te devoro" foi a imposição determinada pelo monstro. "Responda-me: quem de manhã tem dois pés, três à tarde e quatro à noite?" Édipo traduz o enigma: “é o homem”. Horrorizado com a tradução, o monstro atira-se no abismo às suas costas, abrindo passagem para que o jovem caminhe sem o saber, mas agora de fato, rumo ao cumprimento do vaticínio profetizado pelo oráculo.

O enigma da esfinge apresenta outras versões nas quais o jovem tocou o próprio rosto, indicando assim ser ele a resposta. 
De qualquer forma, o contexto narrado permanece, pois, frente à correção da resposta a esfinge busca a morte ao se atirar no abismo. Esse episódio mítico poderia simbolizar o momento da vitória de Édipo, ao utilizar a sua capacidade racional, supremo dom humano, para enfrentar o enigmático presente no desconhecido. Entretanto, a considerar os percalços que o aguardam, e aos quais Édipo é atirado a partir desse episódio, os sentidos a ele atribuídos são passíveis de algum questionamento.

'Enigma' em grego remete a vários sentidos, dentre os quais 'dizer veladamente' ou 'falar por meio-termo'. O enigma da esfinge remete a uma linguagem que se apresentava por meios-termos e, assim, tinha o seu sentido velado. Ainda, em termos políticos, após o seu coroamento como rei tebano, prêmio a que fez jus pela derrota da esfinge, Édipo passa a ocupar o lugar supremo do Rei que amalgama o poder e o saber. Não obstante, a sua trajetória posterior explicita a tragédia que envolve seu poder e seu saber. Assim, o jovem Édipo casa-se com a rainha Jocasta, pois o rei Laio, seu marido anterior, fora morto por estranhos no caminho para Delfos. Dessa união nascem vários filhos e na condição de rei ele exerce o poder por anos, governando em paz e prosperidade.

Entretanto, em dado momento a cidade passa a ser assolada por inúmeros infortúnios, que penalizam a todos os habitantes. O oráculo é consultado e profetiza que o assassinato do rei Laio deve ser desvendado: punir o assassino é a condição para que a paz volte a reinar na cidade. Ora, anos antes, o oráculo profetizara aos pais de Édipo, os reis de Tebas, que ele mataria o pai e se casaria com a mãe, o que os levou a entregar a criança a um pastor e a lhe ordenar que o matasse. Apiedado, em vez de matá-la, o pastor a abandona, e como tal é encontrada pelos reis de Corinto, que a criam como filho. Anos mais tarde, recebendo do oráculo o vaticínio de que estava fadado a matar seu pai e casar-se com sua mãe, Édipo é levado a abandonar Corinto e a empreender uma viagem justamente rumo a Tebas. De forma paradoxal, esse enigma na vida do jovem Édipo condena-o a empreender a busca pela realização do seu trágico destino.

Defronte a tal cenário, o lugar supremo de poder e de sabedoria parece haver abandonado o rei Édipo, que se vê atirado às intempéries do destino e da condição humana. Face aos imprevistos da realidade, a visão que iluminava a compreensão de si e do mundo fica obliterada, e esmorece a razão que o guiava e o esclarecia. Nesse contexto, ocorre a demanda por novos saberes e olhares que possam extrapolar aquele associado à luz da razão que cega. Assim, a tragédia opera como o desvelar da condição humana e como fonte de saber face ao real.

\section{DA RAZÃO, DA TRAGÉDIA}

O trágico configura-se como forma de conceber o real e de produzir conhecimento sobre ele. Para Nietzsche (1998/1992), o trágico comporta tanto os aspectos 
terríveis e enigmáticos da vida quanto congrega as possibilidades da elaboração desses aspectos a partir da arte ou da vontade de potência. A seu ver, a tragédia grega envolvia uma das possibilidades de lidar com o trágico, pois nesse caso a arte expressa na narrativa mítica envolve o absurdo da existência humana, bem como explicita a possibilidade de sujeição via sua transfiguração em sublime.

Por seu turno, a vontade de potência implica o trabalho de reconhecer e aceitar o trágico e o terrível como inerentes à vida humana e, além disso, do homem operar a partir das pluralidades que o constituem. Em outras palavras, o humano e a vida se configuram a partir de pluralidades que se manifestam de várias formas, seja através das leituras diferenciadas utilizadas pelo homem para ler e se relacionar com o mundo, seja através das manifestações da vontade de potência. Nessa perspectiva, é possível observar que o múltipo se contrapõe ao uno e a genealogia da moral contesta o referencial universal que sustenta a ética kantiana e a concepção de conhecimento que subjaz às ciências. Para Nietzsche, a vida é vontade de potência e é possível entender essa concepção como o(s) impulso(s) que mobiliza(m) e sustenta(m) o movimento e a criação do humano.

Ressalte-se que o conceito ‘vontade de potência’ não se aproxima de nenhuma leitura aristotélica, no sentido de expressão de poder ou de causalidade, mas antes, remete à leitura da força como um impulso que emana do humano e o mobiliza, produzindo novas configurações e plasticidades. A vontade de potência pode ser ascendente ou descendente, no sentido de que a primeira busca e promove a vida, e a segunda tende a diminuir o impulso pela vida. Ainda é importante salientar que para Nietzsche o impulso não se constitui em si, não existe como um a priori, pois ele se configura sempre a partir da ação e na relação com o outro. Assim, a concepção da filosofia tradicional baseada na metafísica da presença, na ontologia do identitário e no conhecer amparado pelo sujeito cognoscente universal, desmorona na perspectiva nietzschiana. O mundo é concebido como vida e como um devir, um vir a ser, no qual o embate entre os impulsos acolhe tanto forças afirmativas quanto reativas, o que implica a afirmação de que a vida não se constitui como bem supremo, já que a finalidade não acompanha uma moral (HAAR, 1998).

Para Nietzsche, o método genealógico comporta a concepção do intelecto como uma força voltada para o trágico que, dessa forma, não teme o absurdo e o horrível da existência humana. O trabalho do pensamento encontra seu rigor na empreitada de reconhecer e mesmo buscar o imponderável e o temível da condição humana. Segundo essa leitura o ato do pensar diz respeito a concepções que sustentam a incerteza. Assim, o universal, a certeza e a verdade - como categorias que configuram o real e o método na perspectiva moderna - perdem o sentido face à leitura nietzschiana sobre o real e a vida. O autor repele o pressuposto do fundamento verdadeiro em decorrência do seu vínculo com a 
moral, que se torna necessária, coercitiva e prescritiva. Ainda descarta a busca pelo fim verdadeiro, pela causa primeira, conforme postulada pela filosofia clássica, e critica a moral que acompanha essa leitura, já que ela deságua na moderna concepção de ciência, que elogia a verdade, o universal e a certeza. Vale a pena transcrever a longa citação abaixo (NASCIMENTO, 1998), esclarecedora sobre a relação filosofia, ciência, verdade e expurgo da tragédia.

“A moral impera e se moderniza com a ciência. Aí ela ainda nos convence e parece imprescindível. Mas, em relação a isto vale citar esta afirmação de Nietzsche: 'O conhecimento pelo conhecimento' - eis a última armadilha colocada pela moral: é assim que mais uma vez nos enredamos inteiramente nela' (JGB/BM § 64).

Há pelo menos dois aspectos de esclarecimento decorrentes desta afirmação. O primeiro concerne ao equívoco da ciência de ter interpretado o 'espírito feliz' de descoberta e invenção como conhecimento 'verdadeiro'. Teria de ter interpretado isto como vontade de verdade (...). É preciso adiantar que tal acusação não é feita, propriamente, à ciência e sim à filosofia. O erro da ciência, neste caso, consiste apenas em não ter ido além da noção de verdade enquanto rigor metafísico, enquanto imparcialidade supra-sensível, enquanto princípio verdadeiro. Por não a ter transgredido, a ciência teve de substituir a crença trágica própria da vontade de verdade, pela crença moral na verdade 'primeira', facultada pela metafísica. Com isto não contribuiu para que a filosofia ultrapassasse sua concepção metafísica da verdade. Em consequência disso, também o saber filosófico não pôde propor à ciência a direção de novos axiomas e pressupostos. A acusação é dirigida, pois, à filosofia no sentido de que a ciência depende de pré-condições: 'A rigor, não há ciência 'sem pressupostos'; o pensamento de uma tal coisa é inconcebível...' (GM/ GM III § 24). Se o saber filosófico é requisitado pela ciência nestas circunstâncias, como pôde a filosofia, em determinado momento, adotar aquele rigor da ciência para autocorreção? No entanto, o 'ideal do homem teórico' — a tentativa da filosofia de tomar-se por aquele conhecimento da 'ciência' mesma — , que chega a se fundir com a modernidade, Nietzsche já o encontra em Sócrates (GT/NT § 18). Apesar da potência deste conhecimento, deixa ele claro que, 'quem compreende às avessas, quem se dispõe a pôr a filosofia 'em bases estritamente científicas', precisa antes pôr não só a filosofia, mas também a própria verdade de cabeça para baixo’ (GM/GM III § 24). Este é o segundo aspecto do esclarecimento.” (NASCIMENTO, 1998, p.6)

A vontade de potência expressa o trágico presente na vida e no humano e explicita o modo de se exprimir do homem e do real, que não se pautam por finalidades ou sentidos, definidos ou a serem definidos. O trágico configura e é configurado pela relação vida e humano e pela força que as institui. Não se trata de força, como na perspectiva da física, que expressa uma linha assumindo 
determinada direção e específico quantum de energia. Os conceitos de erro e de engano acompanham a concepção de força e de vontade de potência, já que elas expressam o errático e o devir. Errático, já que não apresenta uma direção a se seguir ou se desvelar; devir, pois não assente na metafísica da substância que acompanha os pressupostos da identidade não contraditória. $\mathrm{O}$ ato de conhecer e o exercício do pensamento se legitimam: o pensar é concebido como exercício de potência, do trágico presente no vir-a-ser, que supera e ultrapassa a verdade amalgamada na moral e nas finalidades.

A tragédia é utilizada como um recurso para explicitar a busca de um saber que não aquele associado à razão cognoscente, conforme constituída pela lógica moderna. A tragédia conforma um saber que atravessa a vida e o ser dos humanos, um saber que vem de longe e de fora, oferecido pelos deuses e não construído a partir de um eu interiorizado e marcado pela razão. Ainda estava longe no tempo a concepção de um eu individualizado e de uma racionalidade marcada pela cognoscência, conforme os ditames dos tempos modernos (CANGUILHEM, 1977; BACHELARD, 1996; BLANCHÉ, 1983; MORIN, 2005a, 2005b, 2005c). Vingava na mítica Grécia a concepção do humano atravessado pelas paixões, representadas por deuses como Eros, Psiquê, Mnemosine, dentre outros. Esses deuses detinham o saber sobre o mundo e sobre o destino dos homens. Por sua vez, os homens poderiam conhecer o que lhes estava predestinado por meio da consulta aos oráculos e de outras experiências reveladoras dos desígnios que os aguardavam. A tragédia conformava um tempo mítico e circular, bem como configurava uma constituição subjetiva na qual o eu era atravessado pelas paixões que portavam um saber sobre a vida. A distância é imensa em reação à subjetividade moderna configurada por um eu racional e individualizado, que se acredita constituído por uma interioridade e conformado pelo embate entre razão e paixão, cabendo à primeira governar a última.

É importante observar que a perspectiva moderna execra a tragédia como constitutiva do real e do método. No cenário moderno a razão é entendida como atributo humano capaz de possibilitar o acesso ao real e de viabilizar a construção de ações pautadas por esse conhecimento. Dessa forma, o saber produzido pelo sujeito epistêmico seria um saber articulado ao universal e à moral, à medida que a capacidade cognoscente possibilitaria ao sujeito tanto o conhecimento sobre o real e sobre si quanto à condição de analisar criticamente o seu entorno e a sua consciência, construindo ações pautadas no bem comum. Esse modo de conceber a constituição subjetiva predomina no mundo moderno e tem sua hegemonia creditada à expansão e disseminação da concepção cartesiana que sobrepõe a subjetividade à consciência e oblitera os limites da razão (ROUANET, 1985, 1987). Dessa forma, leituras sobre a tragédia de Édipo que remetem à concepção do saber como ancorado no pressuposto lógico formal e racional 
parecem-nos insuficientes para compreender a riqueza dessa narrativa. Essa discussão não envolve apenas a questão de anacronia, evidenciada pela leitura do mito a partir de um referencial moderno. Antes, supomos que se encontra em evidência a própria concepção sobre o processo de conhecer, e sobre o sujeito que conhece. No caso o trágico como que acompanha a narrativa mítica.

Conforme sabemos, a tragédia como possibilidade para aceder ao conhecimento foi banida e desqualificada no paradigma moderno. Os parâmetros da filosofia clássica são assentes nos princípios lógicos da identidade (A é A); da não-contradição (A e não-A); do terceiro excluído (A ou não-A); bem como, na causalidade como forma privilegiada de determinismo. Nessa perspectiva, a crescente matematização da lógica engendra o predomínio dos pressupostos axiomáticos (relação causa e efeito; universal; dissociação sujeito e objeto; verdade) e o abandono da perspectiva filosófica e crítica — e passam a dominar o denominado conhecimento científico, desqualificando outras formas de saber (DUBUCS, 2001; MORIN, 2005a, 2005b, 2005c; MATURANA e VARELA, 2001, 1997; PRIGOGINE, 1996; BACHELARD, 1996; BLANCHÉ, 1983; CANGUILHEM, 1977). Podemos supor que a literatura e a psicanálise se constituem nas poucas áreas de conhecimento que continuam a trabalhar com a metáfora e a tragédia como parâmetros privilegiados para lidar com o conhecimento (FÈDIDA; 1992, 1996, 1991, 1988; FREUD, 1900; 1912; 1916; 1930).

Essa questão revela-se importante à medida que as leituras sobre o mito ou sobre a tragédia demandam utilizar referências que fogem ao denominado padrão científico. Assim, a narrativa edípica merece ser escutada a partir de referências outras e de sensibilidades e cognoscências não restritas a concepções modernas. Nessa perspectiva, a tradução do enigma da esfinge realizada por Édipo demanda outros olhares e análises. Assim, a possível resposta para o enigma da Esfinge - que aponta para um discurso coerente quando o jovem responde tratar-se do homem, ou para a ambiguidade da resposta, quando ele responde tocando o próprio rosto — indica diferentes possibilidades de análise.

Podemos supor que Édipo realizou uma tradução do enigma proposto pelo monstro, ou seja, ele foi capaz de aceder ao real vivenciado e representado pela esfinge, bem como aceder aos sentidos do seu discurso, interpretá-lo e traduzi-lo. Caso tomemos essa senda de análise, é possível afirmar que a realidade compartilhada pela esfinge e por Édipo articula-se a um mesmo plano representacional e cognoscente. Ou seja, ambos partilhariam da condição subjetiva e cognoscente que apresenta pontos contínuos, já que essa condição seria o fato de possibilidade para o exercício da tradução. Ora, face a essas questões supomos que foram justamente os pontos de contato e de interseção entre Édipo e a esfinge que possibilitaram ao primeiro compreender e explicitar o discurso e a realidade da última, bem como foram esses mesmo pontos de contato 
que permitiram à última construir um enigma que dizia respeito à realidade humana. Nessa perspectiva, o ponto de contato entre os dois diz respeito a uma condição conhecida de ambos e por eles vivenciada: a condição humana. A humanidade do monstro possibilita-lhe elaborar o enigma; a humanidade de Édipo possibilita-lhe compreender o enigma por ele proposto. Esse cenário explicita o nó górdio do enigma, pois Édipo traduz a condição humana: a sua própria e a do monstro.

Nessa perspectiva, Édipo encontra a possibilidade para realizar a tradução do discurso do outro, quando assumi a tradução do seu próprio discurso alienado e subsumido no outro e pelo outro. Assim, reconhecer e confrontar a irredutibilidade, incompletude e temporalidade da sua condição e do seu próprio discurso, possibilitou-lhe traduzir o discurso do outro. O ponto de encontro deu-se no ato de reconhecer no monstro dilacerado no corpo metade homem e metade animal o trágico da condição humana.

\section{DO OUTRO E DA DIFERENÇA}

Buscar compreender o funcionamento do humano e do real a partir do referencial do outro na perspectiva da política multicultural do diferente face à representação identitária pode redundar na reiteração da mesmidade. Da mesma forma, pode redundar no ato de reconhecimento do outro marcado por uma cultura e por uma dor que o configura e demanda a oferta generosa de compreensão e de tolerância por parte do profissional. Há de se lembrar do outro nomeado como monstro que também abriu caminho ao se deixar traduzir e feneceu pela ação da tradução.

A esfinge monstro apresenta um enigma sobre a condição humana. Ela pensou, falou, viveu e morreu por uma questão que lhe era estranha? A condição humana habita o monstro esfinge e se explicita na angústia frente à pretensa solução do enigma, abrindo margem à continuidade da trágica viagem de Édipo. O trabalho de tradução do jovem Édipo foi reconhecer e confrontar não apenas o horror do outro-monstro marcado pela diferença no diferente — percepção de fácil reconhecimento e emocionalmente aceitável — mas antes, reconhecer e confrontar o horror do outro-monstro marcado pela diferença na representação identitária - percepção que descentra e mobiliza. O primeiro movimento de perceber o diferente, configurado pela estética do espelho, paralisa e imobiliza reiterando o discurso e a representação identitária. O segundo movimento descentra e produz um novo discurso calcado em novas representações identitárias.

Entretanto, ao liberar seu caminho e prosseguir sua jornada, Édipo defrontase com a tragédia prevista pelo oráculo. Frente à morte e às decepções, vê-se novamente confrontado com outro enigma da condição humana, o que lhe possibilita traduzir-se ao traduzir o discurso do outro-oráculo. 
A formação identitária individualizada oferece ao sujeito a crença na certeza sobre o acesso à verdade sobre si e sobre o outro. Assim, esse processo aplaca o medo do sujeito em problematizar sua subjetividade. Reconhecer e tomar contato com o excluído, com a alteridade, no sentido do outro, pode gerar medo. O homem moderno se constitui a partir do estabelecimento da "subjetividade como um eu" e, o individualismo implica a internalização da noção de "eu privatizado". Entretanto, a identidade pode ser pensada como uma ficção construída pelo sujeito, pois a constituição subjetiva acontece a partir de sucessivas identificações desse mesmo sujeito com modelos identificatórios (FREUD; 1916; 1921). A identificação como processo psíquico nos constitui e nos oferece a ilusão de sabermos quem somos e quem é o outro, a partir da constituição subjetiva calcada na representação identitária.

O caminho do universal compreende a contradição e o encontro com o singular, já que o universal não ressoa para todos com a mesma tonalidade, ou seja, ele não é apreendido pelas singularidades da mesma maneira. As diferentes redes culturais estabelecem sentidos e significados para suas práticas. Assim, o trabalho de traduzir, de procurar compreender o sentido que os discursos e os atos assumem para o outro esbarra na dificuldade de que o simbólico utilizado para esse trabalho não se sobrepõe ao que esse outro utiliza. Dito de outra forma, o recurso linguístico expressa significados diferenciados para as culturas e como instrumento utilizado no trabalho de interpretar se modifica em decorrência dessa questão.

O trabalho do pensamento sobre a volta do outro, seja ele denominado de análise ou de interpretação, poderia ser compreendido como uma irrupção, como um acontecimento, no sentido de que alguma coisa irrompe para desfazer o pensamento anterior, para descentrá-lo do si próprio, para produzir a perda das palavras.

Entretanto, o trabalho de reconhecimento do outro pode permanecer na perspectiva identitária e, com isso, restaurar o outro como estrangeiro, inimigo ou vítima. Assim, perde-se a perspectiva relacional e do devir, e ganha corpo a dissonância do outro em contraponto à identidade. Esse cenário abre brechas à benevolência daquele que oferece guarida e tolerância para com o estrangeiro, mesmo quando esse outro não deseja esse respeito e essa hospitalidade (DERRIDA, 1997). Assim, na leitura identitária moderna, a hospitalidade envolve o ato de reconhecer o outro, sua condição de estrangeiro e de estranho, concomitante ao ato de oferecer-lhe abrigo, desde que o lugar de hospedeiro se sobreponha ao lugar de senhor. Nesse contexto, mantêm-se os lugares antagônicos do mesmo e do outro; da identidade que discerne o outro apenas a partir do contraponto com o mesmo e, portanto, pode apenas tolerá-lo e aceitar lhe oferecer ajuda, dita humanitária ou profissional. Assim, 
o sujeito do mesmo, da repetição, que configura a subjetividade moderna na sua ilusão de permanência temporal, conserva sua irredutibilidade.

O outro que Édipo visualiza na esfinge e supõe compreender e traduzir, ao oferecer sentido ao enigma, é um outro sentido e pensado como sua extensão. A representação identitária configura sua subjetividade, levando-o a buscar sentidos repetidos na sua vivência e a enunciar a resposta ao enigma do outro configurado como esfinge. O que se suporta ver no outro é a extensão do "eu", travestido com cores e formatos porventura mais vivazes ou mais esmaecidas. Assim, o outro traduzido e interpretado centra-se na mesmidade, e o monstro imbuído de humanidade oferece guarida ao trágico da condição humana.

A prosseguir com sua travessia, Édipo encontra-se com o sábio (e cego) Tirésias - e os infortúnios que desabam sobre Atenas são paulatinamente desvelados e culminam com a revelação sobre a sua condição trágica de assassino do pai e amante da mãe. Após haver conhecido o absurdo da sua existência, Édipo extirpa os próprios olhos e parte com a filha Antígona para outra travessia. O ato de cegar-se e de abandonar a cidade em companhia da filha explicita sua busca de um outro saber. Seu novo trajeto leva-o até Colono, nos arredores de Atenas. Nesse cenário, o herói cego tem de se haver com uma realidade diferenciada da anteriormente vivida e, para isso, vale-se de sentidos e faculdades humanas outrora negligenciadas. Agora, cego como Tirésias (o sábio), Édipo enxerga melhor e pode realizar a viagem para Colona acompanhado da filha-outro que o reconhece (e se reconhece) na sua irredutível humanidade - de cego, parricida, incestuoso, expatriado; e suporta a diferença presente no diferente, podendo tanto lhe fazer companhia quanto ser acompanhado.

A viagem continua com a descida de Édipo ao ventre da terra para selar o descanso da sua atribulada existência. De Tebas a Colono, a busca por um ventre que o acolha redunda no retorno ao ventre que o consome. Do seio que o expulsou ao seio que se abre para recebê-lo, o tempo transcorreu e trouxe novas marcas que se fixaram no corpo e na alma. A mão da filha que acolheu Édipo e o acompanhou na abertura de novos trajetos se interpôs no destino dos lambidáceas e abriu caminho às novas traduções e sentidos. Afinal, a família dos lambidáceas, da qual descendia Laio, era amaldiçoada pela prática da pedofilia. O destino transgeracional reservado a Édipo se rompe no vínculo estabelecido com o outro-filha. O simbólico deslocouse e agregou outros sentidos ao lugar ocupado pela repetição e pelo espaço saturado pelo tempo coagulado. O tempo vivido e transcorrido no espaço da travessia em companhia do outro ressemantizou o simbólico e pariu um outro nascimento no retorno à terra-mãe. 
A travessia traduz a experiência vivida na relação de amizade e reconhecimento que atravessa os dois viajantes. Prevalece aqui a companhia do outro, reconhecido como a diferença na sua irredutibilidade. O um atravessado pelo outro se interpõe a traduções e demanda vida vivida. O caminho se abre a outras referências e se constrói no caminhar dos caminhantes, assim como a dança se produz no ato de dançar do dançarino.

Recebido em 18/2/2008. Aprovado em 30/5/2009.

\section{REFERÊNCIAS}

BACHELARD, G. (1996) A formação do espírito científico. Rio de Janeiro: Contraponto.

BLANCHÉ, R. (1983) A ciência atual e o racionalismo. Lisboa: Res.

CANGUILHEN, G. (1977) Ideologia e racionalidade nas ciências da vida. Portugal: Edições 70 .

DERRIDA, J. De l'hospitalité: collection Petite Bibliothèque des Idées. Paris: CalmanLévy, 1997.

DUBUCS, J. (2001) “A lógica depois de Russel”, in BLANCHÉ, R. História da lógica. Lisboa: Edições 70.

FÈDIDA, P. (1988) Clínica psicanalítica - estudos. São Paulo: Escuta.

(1991) Nome, figura e memória: a linguagem na situação psicanalítica. São Paulo: Escuta.

(1992) “Tradition tragique du psychopathologique. A propos du pathei mathos de l'Agamemmon", in Crise e contre-transfert. Paris: PUF.

(1996) O sítio do estrangeiro: a situação psicanalítica. São Paulo: Escuta.

FREUD, S. (1973) Obras completas. Madrid: Biblioteca Nueva. (1900) “La interpretación de los sueños”, t. I, p.343-720.

(1912) “Totem y Tabu”, t II, p.1.745-1.850.

(1916) “Lecciones Introductorias al psicoanalisis”, t. I, p.2.1232.412 .

(1921) "Psicologia de las masas y analisis del yo", t. III, p.2.5632.610 .

HAAR, M. (1998) Vida e totalidade natural. Cadernos Nietzsche, n.5. São Paulo: GEN, p.13-37.

MATURANA, H.; VARELLA, F. (2001) A árvore do conhecimento: as bases biológicas do entendimento humano. Campinas: Editorial Psy II.

MATURANA, H.; VARELLA, F. (1997) De máquinas e seres-vivos: autopoiese: a organização do vivo. Porto Alegre: Artes Médicas. 
MORIN, E. (2005a) O Método I: a natureza da natureza. Porto Alegre: Sulina. Sulina. (2005b) O método III : o conhecimento do conhecimento. Porto Alegre:

(2005c) O Método IV: as ideias. Porto Alegre: Sulina.

NASCIMENTO, M.A. (1998) O trágico, a moral, o fundamento. Cadernos Nietzsche, n.4, São Paulo: GEN, p.35-50.

NIETZSCHE, F. (1992) Além do bem e do mal. Prelúdio a uma filosofia do futuro. São Paulo: Companhia das Letras.

(1998) Genealogia da moral. Uma polêmica. São Paulo: Companhia das Letras.

PRIGOGINE, I. (1996) O fim das certezas: tempo, caos e as leis da natureza. São Paulo: Editora da Universidade Estadual Paulista.

ROUANET, P. S. (1985) A razão cativa: As ilusões da consciência de Platão a Freud. São Paulo: Brasiliense.

ROUANET, P. S. (1987) “Razão e paixão”, in NOVAES, A. (Org.) Os sentidos da paixão. São Paulo: Funarte/Companhia das Letras, p.437-467.

SÓFOCLES. (2000) Édipo-Rei. São Paulo: Difel.

\author{
Mériti de Souza \\ meritidesouza@yahoo.com \\ Fernando Aguiar \\ abs@cfh.ufsc.br
}

